\title{
aniki
}

Revista Portuguesa da Imagem em Movimento

Portuguese Journal of the Moving Image

\section{A Arte de Amar, segundo Sérgio Dias Branco}

\section{José Bértolo}

Instituto de Estudos de Literatura e Tradição, Faculdade de Ciências Sociais e Humanas, Universidade Nova de Lisboa

jlbertolo@gmail.com

https://orcid.org/0000-0003-0445-0909

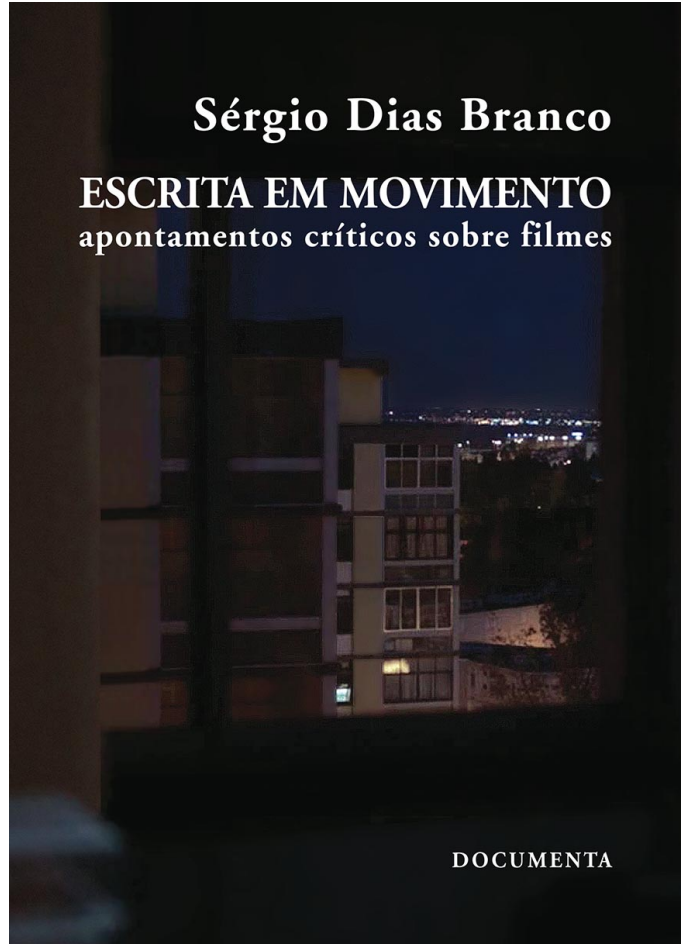

Dias Branco, Sérgio. 2020. Escrita em Movimento: Apontamentos Críticos sobre Filmes. Lisboa: Documenta. 176 pp. ISBN: 9789899006324.

Na introdução de Por Dentro das Imagens, Sérgio Dias Branco comenta a distribuição dos textos que compõem o livro entre "Obras de Cinema" e "Ideias do Cinema" da seguinte forma: "A [...] divisão em duas partes reflecte o modo como ainda hoje o meu trabalho se divide entre a análise e a reflexão" (Branco 2016: 17). Assim, a primeira parte 
integra "análises a obras de cinema, de filmes isolados a grupos de filmes de cineastas", ao passo que a segunda oferece "reflexões sobre ideias do cinema, não aquelas desenvolvidas pelos artistas, mas aquelas que emergem da história e prática do cinema e do pensamento que as tenta acompanhar" (Branco 2016: 17). Dividido entre secções dedicadas ora à análise, ora à reflexão, o livro traça "a história de um espectador que foi descobrindo o cinema, não apenas através da experiência dos filmes, mas sobretudo através do pensamento sobre essa experiência e do registo desse pensamento" (Branco 2016: 16).

Escrita em Movimento: Apontamentos Críticos sobre Filmes, aqui recenseado, apresenta-se como parente próximo do livro anterior. As capas de ambos recorrem a uma imagem e a um grafismo semelhantes. Os dois livros são publicados pela Documenta e as dedicatórias que os abrem também se complementam, visando, a primeira, a mãe do autor, e, a segunda, o pai. No espelhamento entre as duas obras, há, porém, um elemento estrutural que se transforma: se no primeiro caso a "história" deste espectador-autor se faz a partir da junção de um conjunto de reflexões sobre filmes e de um outro conjunto, distinto, mas dialogante com o primeiro, de reflexões de escopo teórico mais geral, o segundo livro compõe-se apenas de análises de obras específicas.

É provável que quem conheça o livro anterior de Sérgio Dias Branco lamente este facto ao perscrutar o índice de Escrita em Movimento, dado que alguns dos momentos de maior fulgor de Por Dentro das Imagens se localizavam, justamente, na segunda secção do livro, por exemplo, na lição de história exemplar do texto "A Política dos Autores, Pensar a Nossa Solidão", na meditação contundente acerca da realidade do cinema em "Verdade e Mentira" (cujos ecos se sentem, porém, no novo livro, como se verá adiante), ou na ousadia de um conjunto de fragmentos sugestivamente intitulado "Cinco Detritos".

Neste primeiro relance sobre o índice do livro de 2020, o leitor nota, ainda, que não só não existe uma divisão em partes, como a ordem dos textos é ditada pelo título dos filmes em análise, alfabeticamente ordenados. Começamos, assim, pelas obras cujos títulos principiam por um algarismo, desses passamos àqueles cujo título inicia com $\mathrm{A}$, e por aí adiante. Este é, portanto, um livro informe, ou, melhor dizendo, que assume uma forma em certa medida fortuita, ditada pela arbitrariedade da letra inicial dos títulos dos filmes. Sendo a princípio perturbador, porque nega, à partida, uma organicidade ao livro que venha "de dentro 
das palavras", ou seja, do universo das ideias, este facto força-nos, porém, num segundo momento, a intuir que Escrita em Movimento, enquanto livro, talvez o seja, porventura, apenas contingencialmente, isto é, ao nível da sua materialidade. Afinal, talvez estejamos perante uma espécie de dossier no qual o autor arquiva (sendo que "o arquivo tem uma dimensão quantitativa, sem estudo nem critério que o sustente" - p. 121) as suas considerações sobre determinados filmes que suscitaram nele o apelo da escrita.

Bem entendido, esta hipótese não desvirtua a obra de Sérgio Dias Branco aqui em foco. Pelo contrário, se o livro anterior se anunciava como uma história de um espectador, esta nova obra, no seu aparente esvaziamento composicional, adquire uma solidez renovada enquanto retrato de um espectador que se torna autor através de uma escrita "em movimento", ditada não por um princípio de construção em particular, mas, sim, por um conjunto de trocas (dir-se-ia tenísticas, invocando Serge Daney, aliás citado no prefácio) assaz pessoais entre Dias Branco e os filmes que vê e sobre os quais escreve. Esta é, aliás, descrita no prefácio como "[a] proposta fundamental deste livro": "que a crítica de cinema é uma conversa entre nós e os filmes" (p. 16). Escrita em Movimento anuncia-se, assim, desde o início, como um conjunto de diálogos. Estas são conversas que nunca ultrapassam as quatro páginas e que, em virtude da sua brevidade, não atingem o nível de desenvolvimento que se pode esperar de uma análise mais extensa. Trata-se, então, sobretudo, da partilha de impressões - por vezes impressionistas, no melhor sentido - que têm, nas palavras do autor, "uma marca de abertura em vez de fechamento" (p. 14). Tal marca constitutiva tem origem, porventura, no facto de estarmos perante um conjunto de textos inicialmente publicados em suportes como revistas, jornais e websites, ou seja, suportes propícios à rapidez e à concisão.

Um aspeto estimulante deste Escrita em Movimento é que a aparente falta de um princípio de construção transfere para o leitor a tarefa de encontrar, na diversidade dos setenta e sete textos que constituem o livro, uma coerência intrínseca, uma lógica em rede ao invés de atomizada. Neste contexto, refira-se, em primeiro lugar, a escrita de Sérgio Dias Branco, sempre sólida, segura, e fiel a um preceito de clareza e funcionalidade que é, a espaços, matizado por laivos de discreto lirismo, sobretudo nos títulos dos textos, sempre penetrantes ("Imagens Arrastadas de Uma Cidade", "A Noite Escura da Fé", "A Orgânica dos Objectos”, “A Encenação da Margem”), mas não só. 
Convoque-se, por exemplo, a conclusão do texto sobre Autografia (2004), de Miguel Gonçalves Mendes: "O seu corpo, onde escorregam gotas de suor e são projectadas imagens, é uma máquina apaixonada iluminada com cores quentes e frias, transparente como o vidro" ( $\mathrm{p}$. 36). Ou uma breve passagem, a propósito de Titanic (1997), de James Cameron: "Cristalino, transparente, negro, o oceano é um cemitério vivo" (p. 153).

Ao nível dos assuntos tratados, o próprio autor identifica, no prefácio, as dimensões religiosa e política como as mais proeminentes nos textos que compõem o livro. No que diz respeito à primeira, ressalve-se a lucidez com que a questão é discutida, por exemplo, nas leituras de Luz de Inverno (1963), de Ingmar Bergman, ou 2001, Odisseia no Espaço (1968), de Stanley Kubrick, a propósito do qual se escreve: "Há um pacto de silêncio que este filme nos impõe. Nada há para explicar, mas sentimos que tudo faz sentido. É uma reflexão sobre o sagrado e o sentido último das coisas. Porquê? Porque aceita a densidade do mistério sem lhe querer dar outro estatuto" (p. 21). Nestas conversas sobre cinema e religião, Dias Branco refere sobretudo o verbo e o silêncio, acabando também, como fica ilustrado na citação acima, por equacionar as próprias opacidades e possibilidades expressivas do cinema. A propósito de Persona (1966), de Bergman, lê-se: "O filme é exterior a nós, mas invade-nos, afecta-nos. Esta opção liga-se à nossa actividade como espectadores. Em vez de exigir a nossa identificação, o filme convida-nos a ouvi-lo e a vê-lo à distância" (p. 86). Por fim, é a mesma "fé cristã" (p. 18), assumida pelo autor no prefácio, que torna particularmente marcante o discernimento revelado na análise de $O$ Caso Spotlight (2015), de Tom McCarthy, filme sobre a problemática dos escândalos sexuais no contexto da igreja, em que se lê: "Talvez seja difícil para muitos católicos assistirem a este filme e confrontarem estes factos. Mas é necessário" (p. 39). Este é o género de pensamentos, tão assertivos quanto frontais na sua formulação, que faz com que o lugar de fala do autor ("Escrevemos a partir daquilo que somos. Escrevemos aquilo que somos. Não há outra forma” - p. 14) nunca perturbe a limpidez do seu olhar, e, antes, a intensifique.

Não obstante a presença manifesta da inquirição religiosa ou metafísica, aquilo que sobressai em Escrita em Movimento é, a nível temático, a dimensão política. Num humanismo sóbrio, cuidadoso, nunca panfletário (porque "[m]ostrar e escutar podem ser gestos mais incisivos do que condenar ou desculpabilizar" - p. 145), e sempre

aniki Recensões| Reviews 
caucionado pelo "projecto socialista" ao qual confessa não ser indiferente (p. 15), Sérgio Dias Branco medita sobre um conjunto de fenómenos históricos e sociais, visibilizando um substrato ideológico que, chegados ao fim da leitura, percebemos ser o verdadeiro pilar deste livro. E, assim, as palavras que o autor escreve a propósito de Palavra e Utopia (2000), de Manoel de Oliveira, podem ser usadas na descrição do seu próprio projeto, se afirmarmos que este livro "mostra como a história é dada a ver [no cinema], não como coisa morta, mas viva, aberta à interpretação e ligada à concepção e vivência do presente" (p. 115).

A matéria política é encarada de frente em obras que, à partida, suscitam essa mesma abordagem, como Okraina (1933), de Boris Barnet, 48 (2009), de Susana Sousa Dias, ou A Fábrica de Nada (2017), de Pedro Pinho. Mas ela surge também, de modo particularmente instigante, em lugares onde não suporíamos encontrá-la à partida, como nas peças dedicadas a Os Prisioneiros da Cave (1991), de Wes Craven, e Transformers 3 (2011), de Michael Bay, perspicazmente analisados enquanto alegorias políticas. Transparecendo uma certa filiação baziniana, o humanismo do olhar de Sérgio Dias Branco fá-lo deter-se, por fim, no problema (entendido aqui enquanto, verdadeiramente, um problema) do realismo cinematográfico, tomado tanto na sua vertente sociopolítica - por exemplo, nos belos textos sobre $O$ que o Céu Permite (1955), de Douglas Sirk, e Natureza Morta (2006), de Jia Zhang-ke -, quanto na sua dimensão estética. É nesta última, aliás, que surgem alguns dos momentos de maior agudeza crítica do livro. Destaque-se os textos sobre Titanic, em que o autor recupera o "labor sobre o cinema como fabricação" (p. 152) de A Verdade da Mentira (1994), o filme anterior de Cameron; sobre Rosetta (1999), de JeanPierre e Luc Dardenne, em que o cinema é equacionado como uma "poesia do concreto" (p. 129); sobre Homem na Lua (1999), onde Milos Forman "lida com a imagem fílmica como uma representação realista, acreditando na sua ambivalência, porque tal imagem é sempre gerada por um olhar" (p. 70); ou sobre Ganhar a Vida (2001), de João Canijo, que nos lembra que "[u]m retrato não é um meio transparente, mas um convite a vermos como alguém viu" (p. 67).

É importante notar a duplicidade ética e estética da visão que Dias Branco tem sobre o realismo cinematográfico, para acautelar que os textos que compõem Escrita em Movimento não são orientados por um olhar exclusivamente conteudístico. Na verdade, a aproximação do 
autor aos filmes conjuga ideias sobre o cinema enquanto meio de representação (do mundo físico, das estruturas sociais e psicológicas) e, também, enquanto meio criativo, codificado, com qualidades expressivas próprias e singulares. É assim que um texto sobre Voo 93 (2006), de Paul Greengrass, dá lugar a uma reflexão sobre um género cinematográfico: "Esqueçamos o 11 de Setembro de 2001 - por enquanto. É preciso deixar essa referência e abordar esta obra como thriller" (p. 163). E é também devido a essa perspetiva a um tempo ética e estética que os textos sobre Gritos 4 (2011), de Wes Craven, e Super 8 (2011), de J.J. Abrams - obras que mostram que "a fantasia pode pulsar de vida" (p. 141) - se afirmam como algumas das mais valiosas peças desta coleção.

Talvez Escrita em Movimento beneficiasse da exclusão de alguns escritos que se afiguram supérfluos, aparentemente mais apressados ou apenas menos desenvolvidos, como aqueles dedicados a Mundo Perdido (1997), de Steven Spielberg, ou As Serviçais (2011), de Tate Taylor. A acrescer a isto, o livro teria a ganhar com um aprofundamento de algumas análises que revelam uma promessa maior do que aquela que cumprem na sua insatisfatória brevidade, como aquelas centradas em Solaris (2002), de Steven Soderbergh, e Fora-de-Jogo (2006), de Jafar Panahi. Por outro lado, se resolvêssemos todos as hesitações, as rugosidades, as ligeiras incongruências que se encontram em Escrita em Movimento, torná-lo-íamos aquilo que ele não é nem deseja ser - um livro convencionalmente polido - e estaríamos, com efeito, a cristalizar aquilo que deve existir, justamente, em movimento. Trata-se, afinal, de um livro sobre cinema que é também, na esteira de Jean Douchet, sobre "a arte de amar" (p. 16).

\section{Referências}

Branco, Sérgio Dias. 2016. Por Dentro das Imagens: Obras de Cinema, Ideias do Cinema. Lisboa: Documenta. . 2020. Escrita em Movimento: Apontamentos Críticos sobre Filmes. Lisboa: Documenta. 